Revista Española de Derecho Internacional Sección PRÁCTICA ESPAÑOLA DE DERECHO INTER-

Vol 70/2, julio-diciembre 2018, Madrid, NACIONAL http://dx.doi.org/10.17103/redi.70.2.2018.3.01 (C) 2018 Asociación de Profesores de Derecho Internacional y Relaciones Internacionales ISSN: 0034-9380; E-ISSN: 2387-1253 Recepción 16.2.2018, evaluaciones 16.4.2018 y 17.4.2018

\section{PRÁCTICA ESPAÑOLA DE DERECHO INTERNACIONAL}

Esta sección podrá albergar Estudios y otros textos doctrinales de extensión más breve referidos a la práctica española en Derecho internacional y Relaciones internacionales. Los Estudios que se publiquen en esta sección habrán sido sometidos al proceso de evaluación por pares y al resto de los requisitos editoriales exigidos para todos los Estudios. Por razón de la materia abordada, en este número se incorpora el estudio de A. Jiménez García-Carriazo que, como tal, ha sido sometido a dicho proceso de evaluación y requisitos editoriales.

\title{
LA PLATAFORMA CONTINENTAL DE LAS ISLAS CANARIAS: AMPLIACIÓN Y CUESTIONES AFINES
}

\author{
Ángeles JimÉnEZ García-CARRIAZO*
}

SUMARIO: 1. INTRODUCCIÓN.-2. LA PLATAFORMA CONTINENTAL Y SU AMPLIACIÓN.2.1. La plataforma continental jurídica.-2.2. El procedimiento de ampliación.-3. LAS ISLAS CANARIAS Y SU PLATAFORMA CONTINENTAL.-3.1. La delimitación entre las islas Canarias y el archipiélago de Madeira.-3.2. La delimitación entre las islas Canarias y la costa marroquí.-4. LA PRESENTACIÓN ESPAÑOLA PARA EL ÁREA OESTE DEL ARCHIPIÉLAGO CANARIO.-4.1. Los límites exteriores de la plataforma continental al oeste de Canarias.-4.2. Cuestiones que surgen al hilo de la presentación.-4.2.1. Las consecuencias de la calificación como isla o roca.-4.2.2. Los espacios marinos de los territorios no autónomos.-5. CONCLUSIONES.

\section{INTRODUCCIÓN}

1. La entrada en vigor de la Convención de las Naciones Unidas sobre el Derecho del Mar ${ }^{1}$ (en adelante, «CNUDM» o «Convención») introduce el derecho a ampliar la plataforma continental más allá de las 200 millas marinas para aquellos Estados que puedan probar la prolongación natural de su territorio bajo el mar. De este modo, los Estados ribereños se aseguran la

* Doctora en Derecho, Universidad de Jaén (angeles.jgcarriazo@gmail.com). Todas las páginas web de referencia han sido consultadas por última vez el 16 de febrero de 2018.

1 Convención de las Naciones Unidas sobre el Derecho del Mar, hecha en Montego Bay (Jamaica) el 10 de diciembre de 1982, BOE núm. 39, de 14 de febrero de 1997. 
exploración y explotación en exclusiva de los recursos naturales presentes en el lecho y el subsuelo marino ${ }^{2}$.

2. Son los propios Estados los que definen los límites exteriores de sus respectivas plataformas y los someten a la Comisión de Límites de la Plataforma Continental («CLPC» o «Comisión»), el órgano encargado de validarlos. Desde 2001, la Comisión ha recibido presentaciones de 68 países que desean determinar unos límites exteriores definitivos, obligatorios y oponibles a los Estados parte de la Convención, para así poder disfrutar de esa área de plataforma continental suplementaria.

3. España ha dividido su presentación en tres sectores, que se corresponden con el mar Cantábrico, el Atlántico noroccidental y el archipiélago canario. En 2009 se confirmó la primera ampliación en la zona del golfo de Vizcaya y el mar Céltico en un proyecto conjunto con Reino Unido, Francia e Irlanda ${ }^{3}$. Ese mismo año, España realizó una segunda presentación para el área de Galicia ${ }^{4}$, que incluía un Área de Interés Común donde el límite exterior había sido fijado de manera coordinada con Portugal. Finalmente, en 2014 la delegación española presentó los datos relativos al límite exterior de la plataforma al oeste de las islas Canarias ${ }^{5}$.

4. La ampliación para Canarias se erige como un excelente modelo de análisis por su complejidad técnica y por despertar controversias y tensiones con los Estados limítrofes. En este trabajo expondremos las lecciones extraídas del procedimiento de ampliación de la plataforma continental del archipiélago canario. El futuro nos dirá si las recomendaciones de la Comisión coinciden con nuestros planteamientos.

\section{LA PLATAFORMA CONTINENTAL Y SU AMPLIACIÓN}

5. El concepto de plataforma continental, pese a existir en su acepción geológica desde el momento de la formación de los mares y océanos, no siempre ha tenido la misma trascendencia desde el punto de vista jurídico. El interés por la plataforma continental surge cuando el mar deja de ser simplemente una vía de comunicación y vehículo para el comercio y, gracias al avance de la técnica, se convierte en un espacio que permite la explotación de importantes recursos naturales.

6. La búsqueda de criterios fiables y estables ${ }^{6}$ con los que definir los límites exteriores de la plataforma continental marcó el ritmo de las negociacio-

\footnotetext{
2 Art. 76 CNUDM.

3 El conocido como proyecto FISU se presentó en 2006 (CLCS.06.2006.LOS) y obtuvo las recomendaciones de la CLPC en 2009.

4 CLCS.47.2009.LOS. La CLPC aún no ha emitido sus recomendaciones.

5 CLCS.77.2014.LOS. La CLPC aún no ha emitido sus recomendaciones.

6 En contraposición a los criterios de profundidad y explotabilidad contemplados por el Convenio sobre la Plataforma Continental de 1958, que fueron objeto de duras críticas por crear un límite inestable.
} 
nes durante la Tercera Conferencia sobre el Derecho del Mar ${ }^{7}$. Se logró una definición consensuada reflejada en el apdo. 1 del art. 76 de la Convención:

«La plataforma continental de un Estado ribereño comprende el lecho y el subsuelo de las áreas submarinas que se extienden más allá de su mar territorial y a todo lo largo de la prolongación natural de su territorio hasta el borde exterior del margen continental, o bien hasta una distancia de 200 millas marinas contadas desde las líneas de base a partir de las cuales se mide la anchura del mar territorial, en los casos en que el borde exterior del margen continental no llegue a esa distancia».

\subsection{La plataforma continental jurídica}

7. La definición de plataforma continental contemplada por la Convención es compleja, pues reúne conceptos geológicos, geomorfológicos y geodésicos, y los traslada a una noción puramente jurídica. El eje fundamental de esta disposición pivota sobre dos datos objetivos: el borde exterior del margen continental y la distancia de 200 millas marinas. El margen continental es un concepto geomorfológico que se corresponde con la prolongación del territorio del Estado ribereño bajo las aguas del mar. Las 200 millas marinas entran en juego cuando el borde exterior no alcanza dicha distancia, creando de este modo una ficción en virtud de la cual la noción de plataforma continental se extiende sin una base geológica que la sostenga.

8. El Estado ribereño cuyo margen continental se extienda más allá de las 200 millas marinas puede ampliar su plataforma continental, siempre que proporcione suficientes argumentos geológicos y geomorfológicos a la Comisión. Este órgano actúa como un panel de revisión científica y técnica de los límites de la plataforma trazados por el Estado ribereño y emite sus recomendaciones al respecto ${ }^{8}$.

\subsection{El procedimiento de ampliación}

9. A través de unas reglas homogéneas, el propio Estado interesado en ampliar su plataforma más allá de las 200 millas marinas calcula el límite exterior de su plataforma continental ${ }^{9}$. Antes de adentrarnos en el estudio

\footnotetext{
Véase Convenio sobre la plataforma continental, hecho en Ginebra el 29 de abril de 1958, BOE núm. 308, de 25 de diciembre de 1971.

${ }^{7}$ La Tercera Conferencia sobre el Derecho del Mar se desarrolló a lo largo de 11 periodos de sesiones entre 1973 y 1982 con el objetivo de elaborar la Convención de las Naciones Unidas sobre el Derecho del Mar.

8 Anexo II CNUDM. El resultado de los análisis de la Comisión se plasma en unas recomendaciones que sirven de base para el posterior trazado del límite exterior de la plataforma continental por el Estado ribereño. Los límites así trazados se convierten en definitivos y obligatorios una vez que el secretario general de las Naciones Unidas los ha dotado de la debida publicidad.

9 Directrices científicas y técnicas de la Comisión de Límites de la Plataforma Continental aprobadas por la Comisión el 13 de mayo de 1999 en su quinto periodo de sesiones, Nueva York, 3 a 14 de
} 
de la plataforma de Canarias, y en aras de facilitar la comprensión de su presentación, esbozaremos brevemente el mecanismo de ampliación de la plataforma continental.

10. El procedimiento se inicia con la ubicación del pie del talud que, salvo prueba en contrario, se entiende como el punto de máximo cambio de gradiente en su base ${ }^{10}$. El pie del talud sirve de punto de referencia para describir las líneas de las fórmulas, cuya línea envolvente marca el borde exterior de la plataforma continental ${ }^{11}$. La conocida como fórmula Gardiner da como resultado una línea formada por puntos fijos localizados allá donde el espesor de los sedimentos es, al menos, el 1 por 100 de la distancia más corta entre ese punto y el pie del talud; la fórmula Hedberg genera una línea trazada en relación con los puntos fijos situados a no más de 60 millas marinas del pie del talud continental.

11. Posteriormente, se evalúa la propuesta a través de la prueba de pertenencia, en virtud de la cual el Estado ribereño debe demostrar que su plataforma continental se extiende más allá de las 200 millas marinas medidas desde las líneas de base ${ }^{12}$.

12. Seguidamente, se aplican las líneas de restricciones, que impiden que la plataforma continental pueda ir más allá de las 350 millas marinas contadas desde las líneas de base o de las 100 millas marinas medidas desde la isóbata de 2.500 metros $^{13}$. El propósito de ambas restricciones es evitar que los Estados ribereños establezcan los límites exteriores de sus plataformas continentales a una distancia desmesurada. Las cordilleras submarinas constituyen un caso de análisis individualizado, ya que están sujetas a

mayo de 1999, CLCS/11 (Directrices científicas y técnicas); NACIONES UNIDAS, Manual de capacitación sobre el trazado de los límites exteriores de la plataforma continental más allá de las 200 millas marinas y para la preparación de presentaciones de información a la Comisión de Límites de la Plataforma Continental, 2006, pp. I-25-I-44.

10 Art. 76.4.b) CNUDM: «Salvo prueba en contrario, el pie del talud continental se determinará como el punto de máximo cambio de gradiente en su base».

11 Art. 76.4 CNUDM: «Para los efectos de esta Convención, el Estado ribereño establecerá el borde exterior del margen continental, dondequiera que el margen se extienda más allá de 200 millas marinas contadas desde las líneas de base a partir de las cuales se mide la anchura del mar territorial, mediante: i) Una línea trazada, de conformidad con el párrafo 7, en relación con los puntos fijos más alejados en cada uno de los cuales el espesor de las rocas sedimentarias sea por lo menos el $1 \%$ de la distancia más corta entre ese punto y el pie del talud continental; o ii) Una línea trazada, de conformidad con el párrafo 7, en relación con puntos fijos situados a no más de 60 millas marinas del pie del talud continental».

12 La Comisión de Límites formula la prueba de pertenencia del siguiente modo: «Si la línea trazada a una distancia de 60 millas marinas desde el pie del talud continental, o la línea trazada a una distancia en que el espesor de las rocas sedimentarias es de por lo menos el $1 \%$ de la distancia más corta desde ese punto hasta el pie del talud, o ambas líneas, se extienden más allá de las 200 millas marinas desde las líneas de base a partir de las cuales se mide la anchura del mar territorial, el Estado ribereño tiene derecho a trazar los límites exteriores de la plataforma continental con arreglo a lo dispuesto en los párrafos 4 a 10 del artículo 76». Directrices científicas y técnicas, apdo. 2.2.8, p. 14 .

13 Art. 76.5 CNUDM: «Los puntos fijos que constituyen la línea del límite exterior de la plataforma continental en el lecho del mar, trazada de conformidad con los incisos i) y ii) del apartado a) del párrafo 4, deberán estar situados a una distancia que no exceda de 350 millas marinas contadas desde las líneas de base a partir de las cuales se mide la anchura del mar territorial o de 100 millas marinas contadas desde la isóbata de 2.500 metros, que es una línea que une profundidades de 2.500 metros». 
una restricción más rigurosa que impide que el límite exterior vaya más allá de las 350 millas marinas ${ }^{14}$. De este modo se evita una extensión excesiva de jurisdicción sobre la plataforma continental.

13. Finalmente, se procede a trazar los límites exteriores de la plataforma continental ampliada, atendiendo tanto al resultado de las líneas de fórmulas como al de las líneas de restricciones. El límite exterior de la plataforma continental es el resultado de unir el límite exterior del margen continental (que a su vez puede ser una combinación de las líneas de las fórmulas) con la línea combinada de las restricciones.

\section{LAS ISLAS CANARIAS Y SU PLATAFORMA CONTINENTAL}

14. Las islas Canarias ocupan una posición geoestratégica privilegiada. Situadas en el océano Atlántico, con una fachada frente a la costa oeste de África, conforman un balcón hacia el continente americano y actúan como lanzadera en las comunicaciones intercontinentales.

15. Geográficamente, el archipiélago canario forma parte de la Macaronesia, región formada por los archipiélagos de Azores, Madeira, Salvajes, Canarias y Cabo Verde. Desde una perspectiva geológica, las Canarias se asientan sobre una zona de transición oceánico-continental sobre la corteza oceánica y muy próxima al límite entre la corteza oceánica atlántica y la corteza continental africana ${ }^{15}$. La configuración volcánica de las islas genera un relieve irregular de costas accidentadas y recortadas.

16. En el plano geopolítico, el archipiélago canario constituye una comunidad autónoma dentro del Reino de España integrada por siete islas principales - Tenerife, Gran Canaria, Lanzarote, Fuerteventura, La Palma, La Gomera y El Hierro-y algunos islotes de origen volcánico — La Graciosa, Alegranza, Montaña Clara, Roque del Este y Roque del Oeste-.

17. La plataforma continental geomorfológica de las islas Canarias es estrecha y sufre un fuerte declive que desciende a grandes profundidades rápidamente. No es especialmente rica en recursos. Así lo han demostrado las prospecciones que la multinacional Repsol ha venido realizando desde el año $2002^{16}$, que han permitido localizar hidrocarburos cuya calidad y cantidad no hacen rentable la extracción. No obstante, en otras campañas desarrolladas

14 Art. 76.6 CNUDM: «No obstante lo dispuesto en el párrafo 5, en las crestas submarinas el límite exterior de la plataforma continental no excederá de 350 millas marinas contadas desde las líneas de base a partir de las cuales se mide la anchura del mar territorial. Este párrafo no se aplica a elevaciones submarinas que sean componentes naturales del margen continental, tales como las mesetas, emersiones, cimas, bancos y espolones de dicho margen».

15 Rodríguez LosadA, J. A., Las islas Canarias y el origen y clasificación de las rocas ígneas, Tenerife, Universidad de La Laguna, 2000, p. 3.

16 Concesión otorgada por el Gobierno español mediante el Real Decreto 1462/2001, de 21 de diciembre, por el que se otorgan los permisos de investigación de hidrocarburos, situados en el océano Atlántico frente a las costas de las islas de Fuerteventura y Lanzarote, BOE núm. 20, de 23 de enero de 2002 . 
por el Instituto Geológico y Minero de España (IGME) y el Instituto Español de Oceanografía (IEO), se han encontrado costras de ferromanganeso que evidencian la presencia de minerales raros y estratégicos formados por las peculiares condiciones de oxígeno, profundidad y actividad volcánica ${ }^{17}$. A esto se suma el hallazgo de un yacimiento de telurio en el monte submarino Tropic $^{18}$, que se sitúa en la zona de ampliación solicitada por España para la plataforma continental del archipiélago canario.

18. La anchura de la plataforma continental canaria se mide desde las líneas de base en el interior ${ }^{19}$ hasta el borde exterior del margen continental o la distancia de 200 millas marinas en el exterior. Resulta conveniente una breve reflexión sobre la proyección de las líneas de base en las islas Canarias.

19. En el archipiélago canario el trazado de las líneas de base se realizó isla por isla, en tanto que constituye un archipiélago de Estado. Este estatus, al contrario de lo que sucede con los Estados archipelágicos, impide que sus espacios marinos puedan medirse desde líneas de base archipelágicas que unan los puntos extremos de las islas y los arrecifes emergentes más alejados del archipiélago ${ }^{20}$. El rechazo a admitir el principio archipelágico para los Estados mixtos fue una de las razones por las que España se abstuvo en la votación de la Convención y retrasó su ratificación hasta $1997^{21}$.

20. La Ley $10 / 1977^{22}$ estableció las líneas de base como el límite interior del mar territorial. Con ayuda del Real Decreto $2510 / 1977^{23}$ se trazaron líneas

Véase GARcía PÉREZ, R., «Las prospecciones petrolíferas en aguas Canarias y su impacto en las relaciones hispano-marroquíes", Revista de Estudios Internacionales Mediterráneos, núm. 13, julio-diciembre de 2012, pp. 1-14; REQUENA CASANOVA, M., "España concede a la empresa Repsol YPF permisos de investigación de hidrocarburos en aguas situadas, en aplicación del método de la equidistancia, más allá del mar territorial de las islas Canarias frente al litoral marroquí», REDI, vol. 54, 2002, núm. 1, pp. 501-505.

17 Se ha encontrado cobalto, níquel, vanadio y tierras raras con itrio, así como trazas de platino, rodio, rutenio y paladio. Marino, E., GonZÁlez, F. J., Somoza, L., LunAR, R., Ortega, L., Vázquez, J. T., REYES, J. y BELLIDO, E., «Strategic and rare elements in Cretaceous-Cenozoic cobalt-rich ferromanganese crusts from seamounts in the Canary Island Seamount Province (northeastern tropical Atlantic)", Ore Geology Reviews, vol. 87, julio de 2017, pp. 41-61.

18 El descubrimiento de este mineral metaloide muy cotizado en la industria tecnológica lo realizó una expedición científica liderada por el Centro Nacional de Oceanografía de Reino Unido, acompañado de miembros del IGME, del Servicio Geológico del Reino Unido, de la Universidad de Southampton y de la Universidad de Sao Paulo.

19 Aunque se mida a partir de las líneas de base, la plataforma continental no comienza a contarse como tal más que a partir del mar territorial.

20 Algunos autores se pronuncian a favor de la aplicación del principio archipelágico a los archipiélagos de Estado. Véase Jiménez PIERnAs, C., "Archipelagic Waters», The Max Planck Encyclopedia of Public International Law, vol. 1, 2012, p. 553; RuIloba GARcía, E., "La delimitación equitativa de los espacios marítimos de los archipiélagos de Estado en Derecho Internacional», Revista Jurídica de Canarias, 2009, núm. 14, pp. 479-496; Jiménez Piernas, C., La revisión del Estatuto Territorial del Estado por el Nuevo Derecho del mar (caso de los Estados archipelágicos), Instituto Alicantino de Cultura Juan Gil-Albert, Universidad de Alicante, 1990.

${ }^{21}$ El instrumento de ratificación fue publicado en el BOE núm. 39, de 14 de febrero de 1997.

${ }^{22}$ Ley 10/1977, de 4 de enero, sobre mar territorial, BOE núm. 7, de 8 de enero de 1977.

23 Real Decreto 2510/1977, de 5 de agosto, sobre trazado de líneas de base rectas en desarrollo de la Ley 20/1967, de 8 de abril, sobre extensión de las aguas jurisdiccionales españolas a 12 millas, a efectos de pesca, $B O E$ núm. 234, de 30 de septiembre de 1977. 
de base recta entre los salientes más acentuados de cada isla, salvo en La Gomera, donde se emplearon líneas de base normal alrededor de toda la isla.

FIGURA 1. Líneas de base recta.

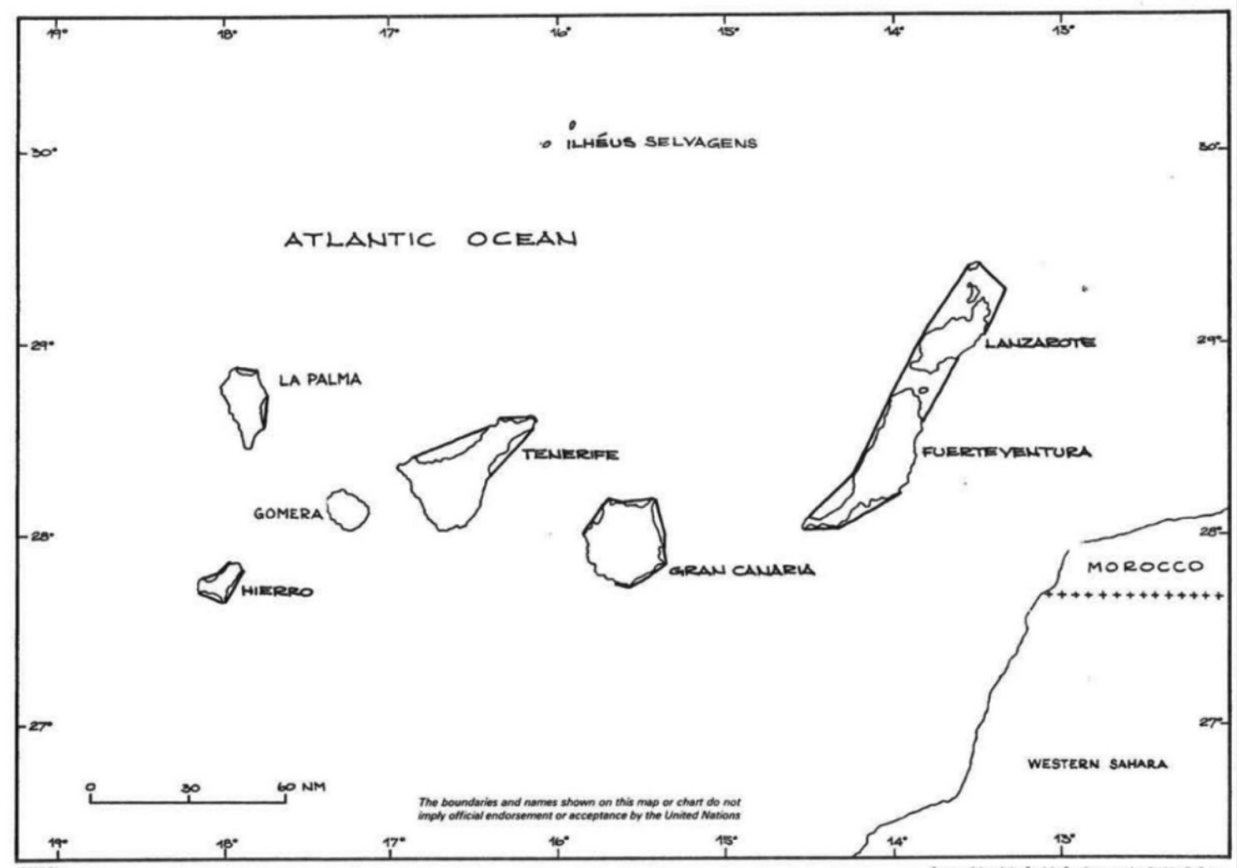

Fuente: NaCIONEs UnIDAs, The Law of the Sea Baselines: national legislation with illustrative maps, Nueva York, 1989 , p. 293.

21. Sin embargo, la posterior Ley $15 / 1978^{24}$, determinó que:

«En el caso de los archipiélagos, el límite exterior de la zona económica se medirá a partir de las líneas de base rectas que unan los puntos extremos de las islas e islotes que respectivamente los componen, de manera que el perímetro resultante siga la configuración general de cada archipiélago».

22. Esta norma, aunque no prevé la derogación de la anterior respecto al mecanismo para establecer las líneas de base en las islas Canarias, la contradice de manera evidente. Pese a contar con la autorización para actualizar el trazado de las líneas, el Gobierno español no procedió a fijar estas líneas de base archipelágicas. Se habría producido un panorama ciertamente incoherente en el que todos los espacios se determinarían desde las líneas de base recta, salvo la zona económica exclusiva, que se mediría desde unas líneas de base diferentes.

${ }^{24}$ Ley 15/1978, de 20 de febrero, sobre zona económica, BOE núm. 46, de 23 de febrero de 1978. 
23. La ratificación de la Convención por España en 1997 parece aclarar la situación, al incorporarse a nuestro ordenamiento un tratado internacional, que prevalecería sobre la anterior Ley 15/1978 ${ }^{25}$.

\section{FIGURA 2. Hipotéticas líneas de base archipelágica.}

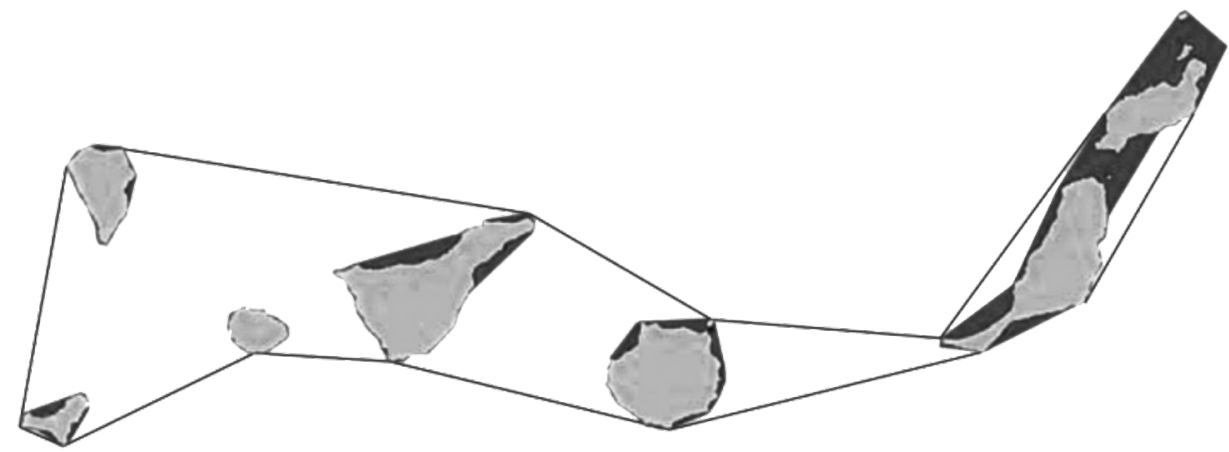

Fuente: Navarro Marchante, V. J., «Problemática jurídica sobre la delimitación de los espacios marítimos del archipiélago canario (a propósito de la Ley 44/2010)», Revista de Derecho Político, vol. 80, Madrid, Universidad Nacional de Educación a Distancia, enero-abril de 2011, pp. 149-186, esp. p. 164.

24. La Ley $44 / 2010^{26}$ vuelve a ensombrecer la realidad. Sin emplear la terminología de la Convención, su único artículo prevé el cierre perimetral mediante líneas de base archipelágicas rectas que rodean unas aguas interinsulares denominadas aguas canarias:

«Entre los puntos extremos más salientes de las islas e islotes que integran, según el artículo 2 de su Estatuto de Autonomía, el Archipiélago canario, se trazará un contorno perimetral que siga la configuración general del archipiélago, tal como se establece en el Anexo de esta Ley. Las aguas que queden integradas dentro de este contorno perimetral recibirán la denominación de aguas canarias y constituyen el especial ámbito marítimo de la Comunidad Autónoma de Canarias».

25. Esta disposición queda privada de eficacia jurídica con la salvaguarda que establece la disposición adicional:

25 El art. 31 de la Ley 25/2014, de 27 de noviembre, de Tratados y otros Acuerdos Internacionales, $B O E$ núm. 288, de 28 de noviembre de 2014, reconoce expresamente la prevalencia de los tratados: «Las normas jurídicas contenidas en los tratados internacionales válidamente celebrados y publicados oficialmente prevalecerán sobre cualquier otra norma del ordenamiento interno en caso de conflicto con ellas, salvo las normas de rango constitucional».

${ }^{26}$ Ley 44/2010, de 30 de diciembre, de aguas canarias, BOE núm. 318, de 31 de diciembre de 2010.

Véanse Orinuela Calatayud, E., "La delimitación de los espacios marinos en los archipiélagos de Estado. Reflexiones a la luz de la Ley 44/2010, de 30 de diciembre, de aguas canarias", REEI, vol. 21, 2011, pp. 1-26; Navarro Marchante, V. J., «Problemática jurídica sobre la delimitación de los espacios marítimos del archipiélago canario (a propósito de la Ley 44/2010)", Revista de Derecho Político, vol. 80, Madrid, Universidad Nacional de Educación a Distancia, enero-abril de 2011, pp. 149-186. 
«El trazado del contorno perimetral no alterará la delimitación de los espacios marítimos de las Islas Canarias tal y como están establecidos por el ordenamiento jurídico español en virtud del Derecho Internacional vigente» ${ }^{27}$.

26. En definitiva, esta regulación, incompatible con la Convención, establece líneas de base archipelágicas. Sin embargo, el efecto queda expresamente excluido al declarar que no se modifica el régimen jurídico internacional vigente. En consecuencia, los espacios marinos canarios, y entre ellos la plataforma continental, se determinan desde las líneas de base definidas en virtud del Real Decreto 2510/1977.

27. En principio, la escasa distancia entre las islas que conforman el archipiélago genera una plataforma continental que se extiende hasta las 200 millas marinas y que rodea a las islas Canarias con una circunferencia casi completa donde ejercitar sus derechos ${ }^{28}$. Pero además, en las aguas adyacentes al suroeste del archipiélago se encuentra un conjunto de montes submarinos de origen magmático, que procede de la misma cordillera de punto caliente que generó las propias islas Canarias ${ }^{29}$. Bimbache, The Paps, Echo, Hijas, Drago, Tropic, Ico, Malpaso, Pelican, Tortuga y otras elevaciones menores pertenecen a la misma región geológica que el archipiélago canario, lo cual permite aplicar el argumento de prolongación natural para solicitar la ampliación de la plataforma continental en esa área ${ }^{30}$.

28. La zona de influencia del archipiélago canario queda limitada por las pretensiones análogas de otros Estados ribereños con los que comparte una frontera marina, a saber, Portugal y Marruecos. Además, conviene recordar que parte del archipiélago canario se localiza frente al territorio del Sahara Occidental. Las implicaciones jurídicas que se derivan sobre la frontera con un territorio no autónomo las estudiaremos bajo el epígrafe 4.2.2.

\subsection{La delimitación entre las islas Canarias y el archipiélago de Madeira}

29. Madeira es un archipiélago atlántico de origen volcánico perteneciente a Portugal. Está constituido por las islas de Madeira y Porto Santo y tres islotes menores deshabitados - Ilhéu Chão, Deserta Grande y Bugio- conocidos como islas Desertas. Políticamente, forman, junto con las

\footnotetext{
27 DA única, Ley 44/2010, de 30 de diciembre, de aguas canarias.

28 Sin perjuicio de las delimitaciones pendientes con los Estados vecinos.

${ }_{29}$ El punto caliente debajo de las islas genera la fusión parcial de las rocas del manto terrestre y da lugar a ascenso de magma al fondo oceánico profundo.

30 Vázouez, J. T., Somoza, L., Rengel, J. A., Medialdea, T., Millán, T., Alcalá, C., González, F. J., Jiménez, P., León, R., López-González, N., Palomino, D., Rodríguez López, F. J., García-Muñoz, M., MaRtín, D., Sánchez-Guillamón, O., Correa, A., Martínez, J. C., Corbalán, A., Cruces, M., García, J. M. y GARcía, M., Informe científico técnico Campaña Drago 0511, Proyecto para la Ampliación de la Plataforma Continental de España al Oeste de las Islas Canarias, Repositorio del IEO, 2011, pp. 7 y 19.
} 
islas Salvajes ${ }^{31}$, la Região Autónoma da Madeira ${ }^{32}$. En esta región política se distinguen claramente dos grandes grupos en función de las características geográficas y geológicas. Desde el punto de vista geográfico se aprecia gran proximidad entre Madeira, Porto Santo y las Desertas, en oposición a lo que ocurre con las Salvajes, que se encuentran más cerca del archipiélago canario. Por otro lado, el primer grupo de islas se sitúa en pleno dominio oceánico, mientras que las islas Salvajes se encuentran, al igual que las islas Canarias, muy cerca de la transición entre la corteza oceánica atlántica y la corteza continental africana ${ }^{33}$.

30. La distancia más corta entre el archipiélago canario (norte de la isla de La Palma) y el archipiélago madeirense (sur de la isla de Madeira) es de 232 millas marinas. El solapamiento entre ambas plataformas continentales es, en teoría, fácilmente salvable a través del principio de equidistancia. Sin embargo, la situación se complica por la presencia de las islas Salvajes a medio camino entre los dos archipiélagos. Las islas Salvajes son rocas deshabitadas no aptas para mantener habitación humana ni desarrollar vida económica propia $^{34}$. Con estas particularidades, y a la luz de la Convención ${ }^{35}$, las Salvajes no pueden proyectar plataforma continental ni zona económica exclusiva.

31. Portugal ha incluido estratégicamente a las islas Salvajes en la región autónoma de Madeira con el objetivo de reconocer la capacidad de estas islas

31 Las islas Salvajes, formadas por Salvaje Grande, Salvaje Pequeña e Islote de Fora, están situadas entre Madeira y Canarias, exactamente a 162 millas marinas al sur del primero de los archipiélagos y a 80 millas al norte del segundo. Fueron descubiertas por el navegante portugués Diogo Gomes en 1438 a su regreso de una expedición a Guinea. Durante siglos, este archipiélago estuvo en manos privadas portuguesas hasta que en 1971 el Estado portugués las adquirió, instituyéndolas como reserva natural.

En 1911 el Ejecutivo español comunicó al portugués que había incorporado estas islas al archipiélago canario. Portugal protestó y, en 1938, la Comisión Permanente de Derecho Marítimo Internacional confirmó la soberanía portuguesa sobre las islas Salvajes. De acuerdo con el dictamen: «Geográficamente, las Salvajes forman un archipiélago autónomo» (citado por Borges GRAçA, P., New challenges of the Atlantic: an approach from Portugal, Lisboa, Center for Public Administration and Public Policies Institute of Social and Political Sciences, Universidade de Lisboa, 2015, p. 126).

Sería en 1997 cuando España finalmente reconociese los derechos en superficie de Portugal sobre las islas Salvajes como resultado de las negociaciones para su integración total en la estructura militar de la Organización del Tratado del Atlántico Norte.

Véase SERENo, A., "El nuevo mapa marítimo de Portugal y el caso de las Islas Salvajes», REEI, vol. 28, 2014, pp. 1-29, esp. p. 20; De CARvalho Coelho CÂNDIDo, A., «A Convenção de Montego Bay e Portugal - Delimitação das Zonas Marítimas da Madeira», Boletim Ensino, vol. 12, 2012, pp. $165-184$.

32 Art. 1 del Estatuto Provisório da Região Autónoma da Madeira, Decreto-lei 318-D/76, de 30 de abril de 1976, Diário do Governo núm. 102/1976: "O arquipélago da Madeira, composto pelas ilhas da Madeira, Porto Santo, Desertas e Selvagens, constitui uma região autónoma da República Portuguesa e é pessoa colectiva de direito público».

33 Mata, J., Fonseca, P. E., Prada, S., Rodrigues, D., Martins, S., Ramalho, R., Madeira, J., Cachão, M., Silva, C. M. y Matias, M. J., "O arquipélago da Madeira», en Dias, R., ARaúJo, A., Terrinha, P., y Kullberg, J. C., Geologia de Portugal, vol. 2, Lisboa, Escolar Editora, 2013, pp. 1485-1540, esp. p. 1487.

34 Lacleta Muñoz, J. M., "La delimitación de los espacios marinos en España: a modo de balance», en MARTín y Pérez de NANClaRes, J. (dir.), España y la práctica del derecho internacional: LXXV aniversario de la Asesoría Jurídica Internacional del MAEC, Escuela Diplomática, 2014, pp. 115-119, esp. p. 118.

35 Art. 121.3 CNUDM: «Las rocas no aptas para mantener habitación humana o vida económica propia no tendrán zona económica exclusiva ni plataforma continental». 
para ampliar el espacio marino portugués ${ }^{36}$. Sin embargo, se trata de una dependencia meramente administrativa, lejos de la unidad geográfica, económica y política que exige el art. 46.b) de la Convención para conformar un archipiélago:

«Por archipiélago se entiende un grupo de islas, incluidas partes de islas, las aguas que las conectan y otros elementos naturales, que estén tan estrechamente relacionados entre sí que tales islas, aguas y elementos naturales formen una entidad geográfica, económica y política intrínseca o que históricamente hayan sido considerados como tal».

32. España niega la trascendencia de las islas Salvajes de cara al trazado del límite entre Canarias y Madeira ${ }^{37}$. La doctrina española presenta distintas soluciones en consonancia con esta postura. Al tratarse de islas con costas opuestas, podría fijarse la línea de equidistancia como frontera desde las líneas de base, bien desde cada isla enfrentada, o bien desde ambos archipiélagos considerados en su conjunto. De este modo, las islas Salvajes quedarían rodeadas por un cinturón de 12 millas marinas dentro de la zona económica exclusiva española ${ }^{38}$. Otra opción sería establecer una línea equidistante, no desde las líneas de base, sino desde las líneas rectas que unen los puntos extremos de las islas que se encuentran frente a frente, evitando así la formación de una zona de enclave en el área española ${ }^{39}$.

33. Como vemos, estos planteamientos abren la puerta a la aplicación de líneas de base archipelágicas a un archipiélago de Estado. Esperanza Orihuela Calatayud estima que:

«solo queremos plantear la duda sobre la posibilidad de facilitar el trazado de la frontera de equidistancia mediante el trazado de estas líneas, que a nadie perjudican y a todos benefician, no pueden considerarse contrario al Derecho internacional, parece lícito y posible unir los puntos más extremos de las islas más alejadas del centro del archipiélago a estos solos efectos» ${ }^{40}$.

36 Carvalho, L. y Leitão, N., "A noção "estratégica” das ilhas Selvagens», GeoINova, vol. 11, Faculdade de Ciências Sociais e Humanas da Universidade Nova de Lisboa, 2005, pp. 267-283; BAEZA BetanCorT, F., Las islas Canarias ante el nuevo derecho internacional del mar, Las Palmas, Museo Canario, 1987, p. 80.

37 El Subsecretario de Asuntos Exteriores, D. Máximo Cajal, alude a una nota verbal enviada por el Gobierno español en su comparecencia ante la Comisión de Asuntos Exteriores de 3 de diciembre de 1991: «En cuanto a Portugal, España se ha opuesto, mediante nota verbal presentada a principios del año 1990, a la pretensión portuguesa, materializada en la Ley 30/1977, de 28 de mayo, sobre Zona Económica Exclusiva y un Decreto-Ley 119/1978, de 1 de julio, que pretende dar zona económica exclusiva a las islas Salvajes, situadas entre Madeira y las islas Canarias. La posición española se basa en que, por tratarse de rocas deshabitadas, la pretensión portuguesa está en contradicción con el derecho internacional del mar, que solo reconoce mar territorial y nunca zona económica exclusiva a estos islotes. Por tanto, no se reconoce la pretensión portuguesa y, consecuentemente, se considera por parte española que en esa área la zona económica exclusiva de las costas canarias llega hasta la mediana con Madeira» (Diario de Sesiones del Senado, IV Legislatura, núm. de expediente 711/000033).

38 Gutiérrez Castillo, V. L., España y sus fronteras en el mar. Estudio de la delimitación de sus espacios marinos, Madrid, Dykinson, 2004, p. 329.

39 Orihuela Calatayud, E., España y la delimitación de sus espacios marinos, Murcia, Secretariado de Publicaciones de la Universidad de Murcia, 1989, p. 204.

40 Orinuela Calatayud, E., «Las islas y archipiélagos españoles en la delimitación de espacios marinos», ADI, Navarra, 1985, pp. 337-358, esp. p. 353. 


\subsection{La delimitación entre las islas Canarias y la costa marroquí}

34. La proyección de plataforma continental del archipiélago canario hacia el este se topa, en menos de 100 millas marinas, con la fachada atlántica de Marruecos ${ }^{41}$. La costa atlántica alauita se extiende a lo largo de unos 1.300 kilómetros desde el cabo Espartel hasta el cabo Juby en un litoral monótono y poco recortado que forma grandes arcos, a veces cóncavos y otras, convexos. La plataforma continental geomorfológica de Marruecos es relativamente ancha y, en casi toda su extensión, una estructura estable, salvo por el foco sísmico localizado frente a las costas de Agadir ${ }^{42}$.

35. El reparto de la plataforma continental a través de una línea equidistante parece sencillo ${ }^{43}$. Ambos Estados apuestan por la regla de la equidistancia para delimitar la zona económica exclusiva ${ }^{44}$, y esta podría aplicarse de forma análoga a la plataforma continental ${ }^{45}$. Sin embargo, el alcance de la regulación interna es bien distinto. Tradicionalmente, Marruecos ha subordinado la aplicación de la equidistancia a las circunstancias particulares de orden geográfico o geomorfológico. De este modo, incorpora sutilmente el criterio de equidad ${ }^{46}$. No obstante, en su nueva propuesta ${ }^{47}$, adapta la delimitación de la zona económica exclusiva a las disposiciones de la Convención, teniendo debidamente en cuenta los factores pertinentes, notablemente geográficos, geomorfológicos y/o circunstancias particulares e intereses nacionales, con el fin de lograr un resultado equitativo. Por el lado español, la Ley 15/1978 (anterior a la CNUDM) aboga por la equidistancia «salvo lo que se disponga en tratados internacionales» ${ }^{48}$. De hecho, España ya empleó la equidistancia

41 LaHlou, A., "Pour une "joint development zone" entre le Maroc et l'Espagne au large des îles Canaries», Annuaire de Droit de la Mer, vol. 14, 2009, pp. 153-170, esp. p. 157.

42 Collignon, J., "Les côtes et le plateau continental marocain», Bulletin de l'Institut des Pêches Maritimes du Maroc, vol. 13, 1965, pp. 21-37, esp. p. 24

43 Véase Espósito Massicci, C., "Sobre el establecimiento de una línea mediana como límite marítimo provisional entre España y Marruecos frente a las costas de las Islas Canarias», Revista Jurídica de la Universidad Autónoma de Madrid, 2006, núm. 13, pp. 91-107.

44 Lacleta Muñoz, J. M., "Las fronteras de España en el mar», Análisis del Real Instituto Elcano, DT, 2004, núm. 34, pp. 1-28, esp. p. 19.

45 Lacleta MuÑoz, J. M., «El Derecho Internacional en los arts. 74 y 83 de la Convención de Montego Bay», en Sobrino Heredia, J. M., Mares y océanos en un mundo en cambio, XXI Jornadas de la AEPDIRI, 2005, Valencia, Tirant lo Blanch, 2007, pp. 199-218.

46 Art. 11 del Dahir 1-81-179 du 8 avril 1981 portant promulgation de la loi 1-81 instituant une zone économique exclusive de 200 milles marins au large des côtes marocaines: «Sans préjudice des circonstances d'ordre géographique ou géomorphologique où, compte tenu de tous les facteurs pertinents, la délimitation doit être effectuée conformément aux principes équitables consacrés par le droit international, par voie d'accord bilatéral entre Etats, la limite extérieure de la zone économique exclusive ne s'étendra pas au-delà d'une ligne médiane dont tous les points sont équidistants».

47 Projet de loi 38-17 modifiant et complétant la loi 1.18 instituant une zone économique exclusive de 200 milles marins au large des côtes marocaines: "La délimitation de la zone économique exclusive du Royaume du Maroc est effectuée sur la base des dispositions de la Convention des Nations Unies sur le droit de la mer adoptée à Montego Bay le 10 décembre 1982, en tenant dûment compte de tous les facteurs pertinents, notamment géographiques, géomorphologiques et/ou de circonstances particulières et des intérêts du Royaume, aux fins de parvenir à un résultat équitable».

48 Art. 2.1 de la Ley 15/1978. Esta ley se aplica según su art. 1 a «los recursos naturales del lecho y del subsuelo marinos», por lo que análogamente podríamos aplicar sus efectos delimitadores sobre la plataforma continental y recurrir de este modo, conforme a la normativa interna, a la equidistancia. 
al definir, de manera unilateral, las coordenadas del espacio sujeto a las prospecciones que mencionamos anteriormente ${ }^{49}$.

36. Teniendo en cuenta la normativa vigente en ambos Estados, España no contempla ninguna circunstancia pertinente que haga que la frontera trazada conforme a la regla de la equidistancia dé lugar a un resultado inequitativo. Sin embargo, la doctrina marroquí propone ajustar la línea de equidistancia teniendo en cuenta las circunstancias de orden geográfico, y muy especialmente, la caracterización de las islas como circunstancia especial $^{50}$ o la concavidad de la costa marroquí entre el cabo de Aguer y el cabo Juby $^{51}$. De este modo, la línea de equidistancia se desplazaría hacia el oeste, acrecentando la plataforma a favor de Marruecos ${ }^{52}$.

37. Finalmente, en el marco de una hipotética delimitación, Marruecos alegaría la especial configuración geológica de su plataforma continental, mucho más amplia que la española. Este argumento quizá tuvo cierto sentido bajo el Convenio sobre la Plataforma Continental de 1958, que establecía la profundidad y explotabilidad como criterios delimitadores. Sin embargo, con el nacimiento del concepto jurídico de plataforma continental, las características geológicas han dejado de ser una circunstancia pertinente y, en consecuencia, no han de ser tenidas en cuenta de cara a la delimitación de la plataforma entre Marruecos y el archipiélago canario ${ }^{53}$.

\section{LA PRESENTACIÓN ESPAÑOLA PARA EL ÁREA OESTE DEL ARCHIPIÉLAGO CANARIO}

38. Desde la ratificación de la Convención en 1997, España cuenta con la facultad de ampliar su plataforma continental más allá de las 200 millas marinas. Durante este tiempo, España ha sometido a la Comisión una pre-

49 Real Decreto 1462/2001. Véase párr. 17.

50 AbDallah, M., Les nouvelles règles du droit international de la mer et leur application au Maroc, París, Librairie Général de Droit et de Jurisprudence, 1981, pp. 34-36.

Este planteamiento está basado en el laudo relativo a la Delimitación de la plataforma continental entre la República Francesa y el Reino Unido de Gran Bretaña e Irlanda del Norte (Reino Unido c. Francia), laudo de 30 de junio de 1977, en el que se estableció que la existencia de las islas Anglonormandas en el Canal de la Mancha constituía, por sí misma, una circunstancia especial. El tratamiento análogo para las islas Canarias significaría que el archipiélago quedaría enclavado con una exigua plataforma continental en la plataforma marroquí. Véase BAEZA BETANCORT, F., op. cit., nota 36, p. 99.

51 Lahlou, A., Le Maroc et le droit des pêches maritimes, París, Librairie générale de droit et de jurisprudence, 1983, pp. 310-311.

52 Orinuela Calatayud, E., España y la delimitación de sus espacios marinos, op. cit., nota 39, p. 222. Esta autora ha analizado las razones esgrimidas por Marruecos para ajustar la línea de equidistancia y concluye que "carecen de fundamento o lo han perdido como consecuencia de la modificación experimentada por el Derecho del Mar». Véase Orinuela Calatayud, E., «La delimitación de los espacios marinos españoles", en Sobrino Heredia, J. M., Mares y océanos en un mundo en cambio, XXI Jornadas de la AEPDIRI 2005, Valencia, Tirant lo Blanch, 2007, pp. 43-72, esp. p. 66.

53 Jiménez García-CARriazo, Á., La ampliación de la plataforma continental más allá de las doscientas millas marinas en el marco de la Convención de las Naciones Unidas sobre el Derecho del Mar - Especial referencia a España, Madrid, Dykinson, 2018, p. 231. 
sentación conjunta con Reino Unido, Francia e Irlanda para el área del mar Céltico y el golfo de Vizcaya en 2006 y dos presentaciones parciales relativas a Galicia y a las islas Canarias en 2009 y 2014, respectivamente ${ }^{54}$.

39. Con el objetivo de trazar los nuevos límites exteriores de la plataforma se creó el Grupo científico y técnico para la ampliación de la plataforma continental española, coordinado por la Comisión Internacional de Límites con Francia y Portugal y la Asesoría Jurídica Internacional ${ }^{55}$ e integrado por científicos del IGME, del IEO, y del Instituto Hidrográfico de la Marina $(\mathrm{IHM})^{56}$.

40. El 17 de diciembre de 2014, España registró la presentación relativa a la plataforma continental al oeste de las islas Canarias, que se expuso de manera oral ante el plenario el 26 de agosto de $2015^{57}$. Previamente, en mayo de 2009, la delegación española había anunciado esta solicitud de ampliación mediante la aportación de información preliminar indicativa de los límites exteriores de la plataforma. De este modo, se cumplía con lo acordado por la Reunión de los Estados parte para evitar el vencimiento del plazo de diez años desde la adopción de las Directrices científicas y técnicas ${ }^{58}$ y se comprometía a realizar la presentación definitiva en el plazo de cinco años ${ }^{59}$.

54 Véase Faramiñán Gilbert, J. M. DE, "Continental shelf and its extension», Spain and the Law of the Sea: 20 years under LOSC, SYbIL, vol. 21, 2017, pp. 267-277.

55 Órganos dependientes del Ministerio de Asuntos Exteriores y Cooperación (MAEC).

56 La delegación original estaba compuesta por el Embajador Pablo de Jevenois Acillona, Presidente de las Comisiones de Límites con Francia y Portugal (MAEC); Concepción Escobar Hernández, Jefa de la Asesoría Jurídica Internacional (MAEC); Juan Manuel de Faramiñán Gilbert, Catedrático de la Universidad de Jaén; Luis Somoza Losada como Coordinador Técnico (IGME); y Teresa Medialdea Cela (IGME), Ricardo León Buendía (IGME), Juan Tomás Vázquez Garrido (IEO), Luis Miguel Fernández Salas (IEO) y Juan Antonio Rengel Ortega (IHM) como parte del equipo científico-técnico. Posteriormente, el Embajador Álvaro Alabart Fernández-Cavada pasó a ostentar la presidencia de las Comisiones de Límites con Francia y Portugal y el Diplomático José Lorenzo Outón se integró al servicio jurídico. En la preparación de la presentación relativa a Canarias cambiaron algunos puestos: José Martín y Pérez de Nanclares pasa a ser el nuevo Jefe de la Asesoría Jurídica Internacional, la Diplomática Ana María Salomón Pérez se convierte en la Presidenta de Comisiones Internacional de Límites con Francia y Portugal y se incorporan a la delegación Francisco Javier González Sanz (IGME), Desirée Palomino Cantero (IEO), Daniel González-Aller Lacalle (IHM), Juan Ramón Conforto Sesto (IHM), Salvador Espinosa González Llanos (IHM), Paloma Sevillano Sánchez (IHM) y Constantino Cid Álvarez (IHM).

Véase FARAMIÑ́́N GILBERT, J. M. DE, «Consideraciones jurídicas sobre la extensión de la plataforma continental (PC) más allá de las 200 (M) millas marinas (algunas referencias a la plataforma continental española)», en Bou Franch, V. E., Juste Ruiz, J. y Sánchez Patrón, J. M., Derecho del mar y sostenibilidad ambiental en el Mediterráneo, Valencia, Tirant Monografías, 902, 2014, pp. 59-86, esp. p. 84; Resumen Ejecutivo de la presentación relativa al oeste de las islas Canarias, p. 12, http://www.un.org/ depts/los/clcs_new/submissions_files/esp77_14/esp_2014_es.pdf.

57 CLCS/90, Progresos en la labor de la Comisión de Límites de la Plataforma Continental, $38 .{ }^{\circ}$ periodo de sesiones, Nueva York, 20 de julio a 4 de septiembre de 2015.

58 Decisión sobre el volumen de trabajo de la CLPC y la capacidad de los Estados, particularmente los Estados en desarrollo, de cumplir lo dispuesto en el art. 4 del anexo II de la Convención de las Naciones Unidas sobre el Derecho del Mar, así como la decisión que figura en el párr. a) del documento SPLOS/72, 20 de junio de 2008, SPLOS/183.

59 Información Preliminar y Descripción del Estado de Preparación, de conformidad con la decisión SPLOS/183, de la Presentación parcial relativa a los límites exteriores de la Plataforma Continental de España en el área al Oeste de las Islas Canarias, p. 47: «España pretende registrar la Presentación 
41. La presentación se elaboró con los datos obtenidos en las seis campañas realizadas entre 2010 y 2014 a bordo de los buques oceanográficos Hespérides, Sarmiento de Gamboa y Miguel Oliver ${ }^{60}$ y la realización de 68.338 kilómetros de batimetría con ecosondas ${ }^{61}$. El especial relieve oceánico adyacente al archipiélago canario justificó este despliegue de medios que pretendía acreditar la continuidad geológica y geomorfológica. El objetivo era demostrar que los múltiples montes submarinos que salpican el lecho adyacente a las islas occidentales son una prolongación natural de Canarias, por lo que geológicamente no pertenecen al continente africano ${ }^{62}$.

42. España comunicó a la Comisión la ausencia de controversias en el área de la plataforma continental objeto de la presentación. Asimismo, informó de que la presentación parcial no prejuzga ni perjudica la fijación del límite exterior de la plataforma resultante de la presentación de Portugal ni los derechos de terceros que puedan ser reclamados en su día ${ }^{63}$. Con la expresión «derechos de terceros» aludía al Sahara Occidental, al que no mencionaba expresamente dadas las delicadas circunstancias jurídicas. No obstante, sí se hacía referencia explícita al margen continental saharaui en la información preliminar transmitida en $2009^{64}$.

43. Los Estados afectados por la propuesta de ampliación se han pronunciado tras la presentación española. Portugal se muestra favorable en tanto que no prejuzgue los límites exteriores de su plataforma continental ${ }^{65}$.

parcial de la Plataforma Continental española más allá de las 200 millas marinas en el área al Oeste de las Islas Canarias, de conformidad con el art. 76 y el anexo II de la Convención de Naciones Unidas sobre el Derecho del Mar, en el plazo de cinco años. En este plazo se pretende terminar el levantamiento batimétrico multihaz contemplado en el "Plan Cartográfico de la ZEE Española" para la ubicación de los puntos del pie del talud, y se desarrollará una campaña de geofísica para la ubicación de los puntos del 1 por 100 de sedimentos», http://www.un.org/depts/los/clcs_new/submissions_files/preliminary/ esp_can_2009_preliminaryinfo.pdf.

${ }_{60}$ Garoe_2010,Drago_2011, Gaire_2011,ZEEE_2011,Amuley_ZEEE_2012 y MAEC_Subvent-1_2013. Se enmarcan en los programas Subvent y Exarcan. Asimismo, se incluyeron datos de batimetría de cuatro campañas del Plan de Investigación Científica de la zona económica exclusiva del Ministerio de Defensa (ZEEE_1999, ZEEE_2000; ZEEE_2011; ZEEE_2012).

61 Martín Y PÉREZ DE NANClares, J., «Plataforma continental ampliada al oeste de las islas Canarias: presentación española ante la Comisión de Límites de la Plataforma Continental», REDI, vol. 68, enero-junio de 2016, núm. 1, pp. 219-226, esp. p. 224.

62 Véase párr. 27. Sánchez-Guillamón, O., Fernández-Salas, L. M., Vázouez, J. T., Palomino, D., Medialdea, T., López-González, N., Somoza, L. y León, R., «Shape and Size Complexity of Deep Seafloor Mounds on the Canary Basin (West to Canary Islands, Eastern Atlantic): A DEM-Based Geomorphometric Analysis of Domes and Volcanoes», Geosciences, vol. 8, 2018, pp. 3-22.

63 Resumen Ejecutivo de la presentación relativa al oeste de las islas Canarias, p. 10.

64 Información Preliminar y Descripción del Estado de Preparación, de conformidad con la decisión SPLOS/183, de la Presentación parcial relativa a los límites exteriores de la Plataforma Continental de España en el área al Oeste de las Islas Canarias, p. 26: «En el polígono meridional, la posible extensión de la Plataforma Continental española podría superponerse con una eventual ampliación más allá de las 200 millas marinas de la plataforma continental del margen continental saharaui».

65 Nota verbal ONU/2015/59, de 1 de abril de 2015: «The Portuguese Government does not object to the Commission considering the submission made by the Kingdom of Spain concerning the outer limits of the continental shelf to the West of the Canary Islands and making recommendations on that basis, to the extent that such recommendations are without prejudice to the establishment of the outer limits of the 
Por su lado, Marruecos ${ }^{66}$, si bien no se opone al examen por parte de la Comisión, sí notifica una serie de reservas a la presentación española ${ }^{67}$. El Reino alauita recuerda que aún no se ha efectuado la delimitación de los espacios marinos entre España y Marruecos y reafirma su compromiso con el principio de equidad. Por otro lado, critica el uso de las líneas de base establecidas en virtud de la Ley 44/2010, de aguas canarias, como punto de partida para trazar el límite exterior de la plataforma. España contesta mediante una nueva nota verbal ${ }^{68}$, aclarando que las líneas de base empleadas son las definidas en el Real Decreto 2510/1977 tal y como se afirma en su presentación ${ }^{69}$.

44. En una posterior nota verbal ${ }^{70}$, Marruecos insiste en la falta de delimitación de sus espacios marinos con España (además de con Portugal, Mauritania y Cabo Verde) y adjunta su transmisión de información preliminar en la que ofrece los primeros datos sobre su potencial plataforma continental más allá de las 200 millas marinas ${ }^{71}$. España no ha respondido a esta nota verbal; sin embargo, en la exposición oral de la presentación, José Martín y Pérez de Nanclares expresa que de las comunicaciones intercambiadas entre España y Marruecos se deduce una posible superposición con una futura presentación relativa a la plataforma continental del Sahara Occidental, territorio no autónomo que está transitando un proceso de descolonización. El delegado español afirma que España está dispuesta a negociar una solución equitativa basada en el Derecho internacional con la entidad que tiene el control soberano de las costas y el territorio del Sahara Occidental, una vez que se considere concluido el proceso de descolonización ${ }^{72}$.

\footnotetext{
continental shelf pursuant to the submission made by Portugal on 11 May 2009, or to the delimitation of the continental shelf between Portugal and Spain".

${ }^{66}$ Cuyo hipotético perjuicio se correspondería con la ampliación de la plataforma del territorio ocupado del Sahara Occidental.

${ }_{67}$ Nota verbal NV/ATL/N.\%/114/2015, de 10 de marzo de 2015: "[T]he Kingdom of Morocco: [...] Emphasizes that the partial submission of the Government of Spain relates to the continental shelf in maritime areas which concern Morocco and Spain and have not yet been delimited; [...] Remains committed in particular to the principle of equity in the delimitation of both the continental shelf and the exclusive economic zone; [...] Notes that the partial submission of the Government of Spain contains information regarding the outer limits of the continental shelf beyond 200 nautical miles in the area to the west of the Canary Islands and, because that distance is measured from the baselines established in Law No. 44/2010 on the waters of the Canary Islands, recalls that the Kingdom of Morocco notified the Government of the Kingdom of Spain at the appropriate time of its reservations related to the Spanish Government's interpretation in that law of the provisions of Part IV of the United Nations Convention on the Law of the Sea of 10 December 1982, concerning archipelagos».

${ }_{68}$ Nota verbal núm. $076 \mathrm{MP} / \mathrm{bcm}$, de 22 de abril de 2015: «El Gobierno de España desea señalar que las líneas de base utilizadas para medir la anchura de la plataforma continental en la Presentación parcial sobre los límites de la Plataforma Continental de España al Oeste de las Islas Canarias son las definidas en el Real Decreto 2510/1977, de 5 de agosto, como se afirma en el punto 7.9 de la Presentación. La Ley 44/2010 no define líneas de base y no ha sido en modo alguno empleada en la elaboración de la Presentación sobre los límites de la Plataforma Continental al Oeste de las Islas Canarias».

69 Véanse párrs. 20-23.

70 Nota verbal NV/ATL/No./325/2015, de 29 de julio de 2015.

71 Briefing paper on the Atlantic continental shelf of the Kingdom of Morocco beyond 200 nautical miles (200 M), http://www.un.org/depts/los/clcs_new/submissions_files/prt44_09/1513044E.pdf.

72 CLCS/90, Progresos en la labor de la Comisión de Límites de la Plataforma Continental, $38 .{ }^{\circ}$ periodo de sesiones, Nueva York, 20 de julio a 4 de septiembre de 2015.
} 


\subsection{Los límites exteriores de la plataforma continental al oeste de Canarias}

45. Para determinar el límite exterior de la plataforma continental al oeste de las islas Canarias se han seguido las pautas marcadas por la Convención y las Directrices Científicas y Técnicas. El resultado es un límite formado por 448 puntos fijos definidos por coordenadas de latitud y longitud de conformidad con el apdo. 7 del art. 76 de la Convención ${ }^{73}$.

46. Desde los 30 puntos del pie del talud determinados como los puntos de máximo cambio de gradiente en la base del talud continental se han aplicado las fórmulas de la distancia y del 1 por 100 del espesor de los sedimentos para hallar los 448 puntos fijos ${ }^{74}$. El punto fijo 1 está localizado en la equidistancia de las 200 millas marinas entre España y Portugal calculada a partir del Roque de Santo Domingo, en la isla de La Palma, y de la Ponta do Pargo, en Madeira. El punto fijo 448 se ubica en la intersección de las 60 millas marinas del punto del pie del talud 30 y la línea de 200 millas marinas de terceros Estados.

47. El límite exterior definido por la combinación de las dos líneas de fórmulas no puede sobrepasar la línea de las 350 millas marinas. Se trata de una ampliación en un área de cordilleras submarinas donde entra en juego el apdo. 6 del art. 76 de la Convención ${ }^{75}$. La categorización del conjunto de montes submarinos adyacente a la isla de El Hierro como «cordilleras formadas por actividades volcánicas relacionadas con el movimiento de la corteza sobre puntos calientes ${ }^{76}$ exige la aplicación de la restricción basada en la distancia. La descripción de las cordilleras que «se componen normalmente de accidentes volcánicos coalescentes o picos submarinos y se encuentran generalmente en la corteza oceánica» ${ }^{77}$ permite extender la definición a todo el complejo de accidentes volcánicos submarinos oceánicos asociados con la formación de las islas Canarias ${ }^{78}$. Fruto de este proceso se obtiene una línea exterior que envuelve un área ampliada de 296.500 kilómetros cuadrados.

73 Art. 76.7 CNUDM: «El Estado ribereño trazará el límite exterior de su plataforma continental, cuando esa plataforma se extienda más allá de 200 millas marinas contadas desde las líneas de base a partir de las cuales se mide la anchura del mar territorial, mediante líneas rectas, cuya longitud no exceda de 60 millas marinas, que unan puntos fijos definidos por medio de coordenadas de latitud y longitud».

${ }^{74}$ Los puntos fijos 2 a 98, 99 a 123, 124 a 131 y 388 a 448 son el resultado de la aplicación de la fórmula Hedberg. Los puntos fijos 262, 263 y 387 son el resultado de la aplicación de la fórmula Gardiner. Véase Resumen Ejecutivo de la presentación relativa al oeste de las islas Canarias, pp. 13-14.

75 Véase párr. 12.

76 VÁzouez, J. T., et al., op. cit., nota 30, p. 18. Directrices científicas y técnicas, apdo. 7.2.1, p. 57.

77 Directrices científicas y técnicas, apdo. 7.2.1, p. 57.

78 Del propio art. 76 CNUDM deducimos que las cordilleras oceánicas no se consideran parte de la prolongación natural de la masa continental del Estado ribereño. Sin embargo, si tales cordilleras oceánicas no se encuentran en el lecho marino profundo, sino más bien en el margen continental, podrían formar parte de la plataforma continental como concepto jurídico. Véase BREKKE, H. y SYMONDS, P., "The Ridge Provisions of Article 76 of the UN Convention on the Law of the Sea», en Nordquist, M., Moore, J. y HeIdar, T., Legal and Scientific Aspects of Continental Shelf Limits, Leiden, 


\subsection{Cuestiones que surgen al hilo de la presentación}

48. Como ya se ha mencionado ${ }^{79}$, una vez que la Comisión emita sus recomendaciones relativas al área al oeste de las islas Canarias, España deberá proceder a una doble delimitación, con Portugal al norte de la isla de La Palma y con el Sahara Occidental al sur de la isla de El Hierro. La presencia de las islas Salvajes y el hipotético solapamiento con la plataforma continental ampliada de un territorio no autónomo nos plantea dos interrogantes que dificultan la delimitación: la calificación como isla y la ausencia de interlocutor válido.

\subsubsection{Las consecuencias de la calificación como isla o roca}

49. La delimitación de la plataforma continental entre Madeira y las islas Canarias se ve afectada por la presencia a medio camino de las islas Salvajes. Aunque el conflicto de soberanía sobre las islas quedó superado tras el reconocimiento del control terrestre del archipiélago a Portugal ${ }^{80}$, la actual controversia se centra en la habitabilidad del archipiélago y sus consecuencias ${ }^{81}$.

50. La condición de isla la otorgan unos criterios vagos y poco preci$\operatorname{sos}^{82}$. De acuerdo con el apdo. 1 del art. 121 de la Convención, una isla es una «extensión natural de tierra, rodeada de agua, que se encuentra sobre el nivel de esta en pleamar» cuyos espacios marinos se determinan de conformidad con las disposiciones de la Convención aplicables a otras extensiones terrestres. Por su lado, el apdo. 3 del art. 121 de la Convención establece que «las rocas no aptas para mantener habitación humana o vida económica propia no tendrán zona económica exclusiva ni plataforma continental». Elementos

Boston, Martinus Nijhoff, Brill, 2004, pp. 169-197, esp. p. 183. Información Preliminar y Descripción del Estado de Preparación, de conformidad con la decisión SPLOS/183, de la Presentación parcial relativa a los límites exteriores de la Plataforma Continental de España en el área al Oeste de las Islas Canarias, p. 24.

79 Véase párr. 42.

80 Aun así, llama la atención que, en su transmisión de información preliminar, España incluyese las islas Salvajes como parte del archipiélago canario: «El Archipiélago Canario está constituido por un conjunto de siete islas principales, junto con varios islotes (entre ellos las Islas Salvajes) y al menos una docena de montes submarinos situados tanto al norte (Lars, Anika, Dacia, Concepción) como al sur (Las Hijas, Echo) del archipiélago».

Información Preliminar y Descripción del Estado de Preparación, de conformidad con la decisión SPLOS/183, de la Presentación parcial relativa a los límites exteriores de la Plataforma Continental de España en el área al Oeste de las Islas Canarias, p. 11.

${ }^{81}$ Con el fin de legitimar su pretensión, el Gobierno luso ha enviado una escueta delegación del Cuerpo de Vigilantes de la Naturaleza, a los que considera como habitantes de la isla.

82 Véanse Brown, E. D., Sea-Bed Energy and Minerals: The International Legal Regime; Volume 1 The Continental Shelf, Leiden, Boston, Martinus Nijhoff, Brill, 1992, pp. 38-39; KoLB, R., «L'interprétation de l'article 121, paragraphe 3, de la Convention de Montego Bay sur le Droit de la Mer: les rochers qui ne prêtent pas à l'habitation humaine ou à une vie économique propre», AFDI, vol. 40, 1994, pp. 899908; KwiatKowsKa, B. y Soons, A., «Entitlement to maritime areas of rocks which cannot sustain human habitation or economic life of their own», NYIL, vol. 21, 1990, pp. 153-173. 
difusos como la habitabilidad y la viabilidad económica dificultan la caracterización como isla y ofrecen una definición a contrario de roca.

51. El laudo en el asunto del Mar de la China Meridional ${ }^{83}$ crea aún más confusión. El Tribunal arbitral emplea el término genérico «accidente emergido en pleamar» para referirse a las islas y le aplica un test descalificativo con el objetivo de determinar si puede tener plataforma continental y zona económica exclusiva. El resultado dará lugar a «rocas» (si no cumplen con el requisito de la habitabilidad y el desarrollo de actividad económica) o a «islas de pleno derecho».

52. La trascendencia de la habitabilidad o inhabitabilidad en el caso de las islas Salvajes reside en la capacidad para proyectar plataforma continental. Si las Salvajes son consideradas como islas habitables, podrán generar zonas marinas de gran potencial económico y bajo jurisdicción portuguesa ${ }^{84}$. Por el contrario, la caracterización como rocas reduce la extensión marítima lusa a un mar territorial de 12 millas marinas.

53. Lo cierto es que las islas Salvajes carecen de los medios adecuados para desarrollar una habitación sostenible o una vida económica sin ayuda externa. Este hecho fue puesto de relieve en una desafortunada protesta enviada por España ${ }^{85}$ contra la presentación lusa en la que, según el Gobierno español, Portugal comunicaba su deseo de que la plataforma continental de las Salvajes fuese reconocida. Realmente, la presentación portuguesa no hace referencia alguna a las islas Salvajes ${ }^{86}$.

54. No parece que la alusión a las islas Salvajes tenga especial impacto en el tratamiento de las pretensiones españolas y portuguesas ante la Comisión, pues en ninguna de las presentaciones esa área se ve afectada. La mera observación de un mapa nos muestra que las áreas de ampliación de plataforma continental de las islas Canarias y el archipiélago de Madeira no

${ }^{83}$ Mar de la China Meridional (República de Filipinas c. República Popular China), caso 2013-19, laudo de 12 de julio de 2016, apdo. 280.

84 Véase Quartin GraçA, P., «Ilhas Selvagens, a disputa da última fronteira», en Chantal RiBEIRo, M., 20 anos da entrada em vigor da CNUDM: Portugal e os recentes desenvolvimentos no Direito do Mar, Actas da Conferência realizada na Faculdade de Direito da Universidade do Porto em 29 de Outubro de 2014, pp. 21-36.

${ }^{85}$ Nota verbal núm. $186 \mathrm{FP} /$ ot, de 5 de julio de 2013: «España no acepta que las Islas Salvajes generen en modo alguno zona económica exclusiva; sí acepta en cambio que generen mar territorial, ya que las considera rocas con derecho únicamente a mar territorial». Reitera que «no existe aquiescencia española en una eventual delimitación de las zonas económicas exclusivas entre Madeira y las islas Canarias».

86 Nota verbal núm. ONU/2013/153, de 6 de septiembre de 2013: «A oeste do arquipélago da Madeira constitui o prolongamento natural do território emerso da ilha da Madeira e do território de Portugal Continental [e] não inclui o prolongamento natural do território emerso das ilhas Selvagens devido à sua localização natural [...]. Em resultado disso, as ilhas Selvagens não estão refletidas, em nenhuma circunstância, na proposta portuguesa à $C L P C$ ». Además, en la parte final de la comunicación portuguesa, se adiciona que el Estado portugués: "Confirma ausência de disputas por resolver com Espanha, apesar de não haver acordo sobre as fronteiras marítimas entre Portugal e Espanha».

Véase Santana, J., A Importância das Ilhas Selvagens, Instituto da Defensa Nacional, marzo de 2016, p. 14. 
son coincidentes. Puede que la única intención de la protesta española fuese poner de nuevo de manifiesto el asunto inconcluso de las islas Salvajes. En todo caso, se trata de una cuestión de delimitación de plataforma continental hasta las 200 millas marinas en la que la habitabilidad o no de las islas será el factor clave. Esta idea es coherente con la posterior nota verbal remitida por España ${ }^{87}$ en la que informa a la Comisión de Límites de que «no plantea ninguna objeción a la solicitud realizada por Portugal para que la Comisión considere la documentación de su Presentación relativa al Área de las Islas de Madeira».

55. Sea como fuere, el asunto parece estar lejos de resolverse. En última instancia, las discrepancias entre España y Portugal podrían tener dos efectos: por un lado, la dilación del proceso para recibir las recomendaciones de la Comisión de Límites, que tendrá que asegurarse que las reivindicaciones sobre las islas Salvajes no comprometen su actuación; por otro lado, que esta cuestión abandone la órbita internacional y el intercambio de mensajes a través de las Naciones Unidas para quedar sujeta a negociaciones de ámbito bilateral ${ }^{88}$.

\subsubsection{Los espacios marinos de los territorios no autónomos}

56. El Sahara Occidental es un territorio no autónomo bajo supervisión del Comité Especial de Descolonización de las Naciones Unidas ${ }^{89}$. Localizado en el norte de África, se encuentra rodeado por el océano Atlántico, Mauritania, Marruecos y Argelia y comparte una frontera marítima con España a través de las islas Canarias.

57. Durante casi un siglo (1884-1976), el Sahara Occidental fue colonia española. En la década de los sesenta, se promueven las primeras tentativas para descolonizar el territorio mediante la celebración de un referéndum de autodeterminación ${ }^{90}$. Tras un intento frustrado del Reino alauita de integrar el Sahara Occidental en su territorio acudiendo a la jurisdicción consultiva de la Corte Internacional de Justicia ${ }^{91}$, los hechos se precipitaron con la Marcha Verde y la ocupación marroquí. En 1975, España transfirió la administración de la antigua provincia del Sahara español a Marruecos y a Mauritania ${ }^{92}$. El

87 Nota verbal núm. $064 \mathrm{MPbcm}$, de 7 de abril de 2015.

88 SEREno, A., op. cit., nota 31, pp. 23-24.

89 Resolución de la Asamblea General de las Naciones Unidas 2.072 (XX), de 16 de diciembre de 1965.

90 Resolución de la Asamblea General de las Naciones Unidas 2.229 (XXI), de 20 de diciembre de 1966.

91 Corte Internacional de Justicia, Sahara Occidental, opinión consultiva de 16 de octubre de 1975 (C.I.J. Recueil 1975, p. 12). La Corte Internacional de Justicia consideró que, pese a la existencia de vínculos jurídicos entre el sultán de Marruecos y algunas poblaciones nómadas del Sahara Occidental, así como entre los territorios de Mauritania y el Sahara Occidental, la naturaleza de esos lazos no implicaba en ningún caso ni soberanía ni propiedad legítima sobre el territorio.

92 Mediante el Acuerdo Tripartito de Madrid, firmado entre España, Marruecos y Mauritania el 14 de noviembre de 1975, España transfirió la administración del Sahara Occidental a una administración temporal tripartita compuesta por España, Marruecos y Mauritania. 
devenir de los acontecimientos tomó un cariz muy distinto para cada actor involucrado en el proceso ${ }^{93}$ : las tropas españolas abandonaron el territorio el 26 de febrero de 1976; entre tanto, el grupo rebelde saharaui Frente Polisario proclamó la República Árabe Saharaui Democrática (RASD), lo que desembocó en un conflicto armado con Marruecos y Mauritania que se prolongó hasta 1991. El Sahara Occidental continúa hoy día bajo poder de facto marroquí.

58. En lo que respecta a la delimitación de los espacios marinos, el conflicto de soberanía impide avances en la materia. Las negociaciones tendentes a la delimitación exigen un representante legitimado de los intereses del Sahara Occidental. A la luz de los postulados de derecho internacional, Marruecos no puede ser considerado como interlocutor válido para tratar estas cuestiones en nombre del Sahara Occidental ${ }^{94}$.

59. Aun así, como territorio no autónomo, el Sahara Occidental puede disponer libremente de sus riquezas y recursos naturales, incluidos los marinos ${ }^{95}$. Además, se condenan las actividades de los países colonialistas que aprovechan los recursos del territorio bajo dominación colonial para su propio enriquecimiento y con el fin de obstaculizar la concesión de independencia ${ }^{96}$.

60. No obstante, los últimos pasos emprendidos por Marruecos se encaminan en sentido contrario. Los nuevos proyectos de ley adoptados en julio de 2017 son muestra de un espíritu expansionista que pretende incluir el espacio marítimo frente a la costa del Sahara y el control de las aguas en el ordenamiento jurídico alauita ${ }^{97}$. De esta acción se puede deducir que la presentación para ampliar la plataforma continental marroquí incluirá el territorio del Sahara Occidental ${ }^{98}$.

93 Véase FLORY, M., «L' Avis de la Cour Internationale de Justice sur le Sahara Occidental», AFDI, vol. 21, 1975, pp. 253-277; VIllar, F., El proceso de autodeterminación del Sahara, Madrid, Editorial Fernando Torres, 1982.

94 Casado Raigón, R. y Gutiérrez Castillo, V. L., «Marruecos y España. La delimitación de sus espacios marítimos», en MARIÑo MEnÉndez, F., El Derecho internacional en los albores del siglo XXI: homenaje al profesor Juan Manuel Castro-Rial Canosa, Madrid, Trotta, 2002, pp. 85-106, esp. pp. 101-102.

95 Resolución de la Asamblea General de las Naciones Unidas 1.514 (XV), de 14 de diciembre de 1960; Acta final de la Tercera Conferencia de las Naciones Unidas sobre el Derecho del Mar: «En el caso de un territorio cuyo pueblo no haya alcanzado la plena independencia u otro régimen de autonomía reconocido por las Naciones Unidas, o de un territorio bajo dominación colonial, las disposiciones concernientes a derechos e intereses con arreglo a la Convención se aplicarán en beneficio del pueblo del territorio con miras a promover su bienestar y desarrollo».

96 Resolución de la Asamblea General de las Naciones Unidas A/RES/36/51, de 24 de noviembre de 1981. Esta resolución, originalmente destinada al África Meridional, resulta aplicable al Sahara Occidental. En relación con los recursos marinos, destaca especialmente la enérgica condena a Sudáfrica «por su extensión ilegal del mar territorial y su proclamación de una zona económica frente a la costa de Namibia».

97 Véanse Aclaraciones del portavoz del Ejecutivo, Mustapha El Khalfi, tras el Consejo de Gobierno de 6 de julio de 2017. FILAKI, K., para Le Desk de 7 de julio de 2017, Domaine maritime: les enjeux de l'approche du Maroc au Sahara: "Ces textes visent à inclure l'espace maritime faisant face aux côtes du Sahara dans l'arsenal juridique national, pour cimenter la tutelle juridique du Maroc sur ces eaux et barrer la route à toutes les allégations remettant en cause la souveraineté du Royaume sur cet espace».

98 La presentación de Marruecos había sido anunciada para el mes de mayo de 2017. 
61. Por su parte, la RASD también se ha erigido en protagonista. En enero de 2009, proclamó las zonas marinas del Sahara Occidental mediante la Ley $3 / 2009^{99}$, en la que adopta un papel primordial en la negociación de las delimitaciones que afecten a las aguas del Sahara Occidental. Los efectos de esta reclamación jurisdiccional son cuestionables en tanto que la RASD no es un Estado y, por tanto, no está legitimada para proceder a la delimitación. No obstante, esta propuesta, además de traer de nuevo a primer plano la paralización de la descolonización, pretende denunciar que Marruecos carece de legitimidad para delimitar los espacios marinos del Sahara Occidental ${ }^{100}$.

62. La cantidad de actores implicados y títulos sobre el terreno, junto con las cuestiones territoriales pendientes, no presagian una solución a corto plazo y ponen en peligro el procedimiento de determinación del límite exterior de la plataforma continental ante la Comisión. El enquistamiento del conflicto del Sahara Occidental y la hipotética inclusión de la plataforma continental saharaui en la presentación de Marruecos podrían llegar a retrasar, o incluso a impedir, las recomendaciones de la Comisión para España.

63. La postura que Marruecos adopte en su presentación es clave para la evolución de la cuestión. La inclusión de las aguas y espacios marinos del Sahara Occidental intensificaría el nivel de tensión entre el Reino alauita y la antigua colonia española. El caso contrario crearía nuevas perspectivas dirigidas a la resolución.

\section{CONCLUSIONES}

64. La ampliación de la plataforma continental de las islas Canarias es una magnífica oportunidad para reforzar los derechos soberanos de España sobre nuevos recursos marinos y para lograr un entendimiento con los Estados vecinos. El aumento de la proyección del territorio de Canarias hacia el oeste se traduce en el acceso a potenciales recursos estratégicos y en la consolidación de la presencia española en la escena internacional al disfrutar de manera exclusiva de derechos de exploración y explotación sobre este área. Por otro lado, la delimitación de la plataforma continental con los Estados limítrofes introduce un elemento de tensión, pues España, Portugal y Marruecos se ven "obligados a entenderse», bien a través de un acuerdo, bien recurriendo a un medio pacífico de solución de controversias ${ }^{101}$.

99 Loi n. ${ }^{\circ}$ 03/2009 du 21 janvier 2009 établissant les zones maritimes de la République Arabe Saharaouie Démocratique. Art. 11: «Lorsque les droits maritimes de la République Arabe Sahraouie Démocratique se superposent aux droits maritimes des états voisins, la République Arabe Sahraouie Démocratique peut négocier et conclure des accords avec les états voisins en ce qui concerne les délimitations maritimes».

100 Riguelme CoRTAdo, R., La soberanía permanente del pueblo saharaui sobre sus recursos naturales, Cursos de Derecho Internacional y Relaciones Internacionales de Vitoria-Gasteiz, 2011, pp. 385450, esp. p. 427.

101 Art. 83 CNUDM: «1. La delimitación de la plataforma continental entre Estados con costas adyacentes o situadas frente a frente se efectuará por acuerdo entre ellos sobre la base del derecho internacional, a que se hace referencia en el artículo 38 del Estatuto de la Corte Internacional de Justicia, 
65. La delimitación de la plataforma continental hasta las 200 millas marinas entre las islas Canarias y Madeira se complica por la presencia de las islas Salvajes. Estos islotes son considerados como rocas por España, a la luz del apdo. 3 del art. 121 de la Convención, y como islas por Portugal, que afirma su capacidad para mantener habitación humana y desarrollar actividad económica. La ausencia de criterios suficientemente objetivos para caracterizar una isla aviva la polémica. Sin embargo, la cuestión de las islas Salvajes no afecta a la delimitación de la plataforma continental ampliada y tanto España como Portugal han proporcionado las suficientes garantías, con excepción de la desacertada nota verbal española, de que las presentaciones no prejuzgan cuestiones relativas a la fijación de los límites entre Estados.

66. La delimitación entre las islas Canarias y la costa occidental africana se ve obstaculizada por la presencia de un territorio no autónomo. Esta situación plantea varios escenarios:

- Si la Comisión acepta el límite exterior de la plataforma continental tal como ha sido definido por España en su presentación, el área de solapamiento no contará con un límite definitivo en tanto que la delimitación lateral esté pendiente. Además, el límite no será oponible al Sahara Occidental, ya que no es Estado parte de la Convención.

- Si Marruecos llegara a incluir explícitamente en su presentación la ampliación de la plataforma continental que corresponde al Sahara Occidental, es improbable que se le reconozcan facultades de negociación en nombre de los intereses saharauis, por lo que la Comisión descartaría el análisis. Si bien es cierto que el Acuerdo de Pesca de 1 de agosto de $1983^{102}$ y el Acuerdo de colaboración entre la Comunidad Europea y el Reino de Marruecos en el sector pesquero ${ }^{103}$ podrían interpretarse como un reconocimiento implícito a la soberanía marroquí, se trata de un argumento débil y jurídicamente cuestionable ${ }^{104}$. En consecuencia, la solución habría que encontrarla en la vía jurisdiccional o en la negociación bilateral.

a fin de llegar a una solución equitativa. 2. Si no se llegare a un acuerdo dentro de un plazo razonable, los Estados interesados recurrirán a los procedimientos previstos en la Parte XV».

102 El Acuerdo de Pesca hace referencia a las aguas situadas al sur del cabo Noun.

103 Acuerdo de colaboración en el sector pesquero entre la Comunidad Europea y el Reino de Marruecos, Protocolo entre la Unión Europea y el Reino de Marruecos por el que se fijan las posibilidades de pesca y la contrapartida financiera previstas en el Acuerdo de pesca y Reglamento (UE) núm. 1270/2013 del Consejo, de 15 de noviembre, relativo al reparto de las posibilidades de pesca en virtud del Protocolo de 2013, DOUE-L-2013-82736.

104 En este sentido, el Abogado General Wathelet considera que el Acuerdo de pesca celebrado entre la Unión Europea y Marruecos no es válido por aplicarse al Sahara Occidental y a las aguas adyacentes. Al celebrar dicho Acuerdo, la Unión incumplió su obligación de respetar el derecho del pueblo del Sahara Occidental a la libre determinación y su obligación de no reconocer una situación ilegal resultante de la vulneración de dicho derecho, además de no instaurar las garantías necesarias para garantizar que la explotación de los recursos naturales del Sahara Occidental redunde en beneficio del pueblo de dicho territorio. Conclusiones del Abogado General de 10 de enero de 2018, The Queen y Western Sahara Campaign/Secretary of State for Environment, Food and Rural Affairs y Commissioners for Her Majesty's Revenue and Customs, C-266/16, ECLI:EU:C:2018:1.

Sin embargo, el Tribunal de Justicia de la Unión Europea considera que el acuerdo es válido, puesto que no es aplicable al Sahara Occidental ni a las aguas adyacentes a este, dado que, habida cuenta 
67. Lo que queda claro es que, en tanto que el Sahara Occidental siga siendo una colonia sin un representante legitimado para defender sus intereses, los remedios que se diseñen no serán definitivos.

68. En definitiva, la aplicación individualizada al caso de Canarias nos muestra la cantidad de vicisitudes que influyen en el procedimiento de ampliación. Pese a la existencia de unas normas de base geológica y geomorfológica, las cuestiones de carácter jurídico y político se entremezclan en cada etapa del procedimiento.

\section{RESUMEN}

\section{LA PLATAFORMA CONTINENTAL DE LAS ISLAS CANARIAS: AMPLIACIÓN Y CUESTIONES AFINES}

La Convención de las Naciones Unidas sobre el Derecho del Mar prevé la posibilidad de que los Estados ribereños amplíen su plataforma continental más allá de las 200 millas marinas. Se crea así un espacio marino suplementario donde los Estados pueden explorar y explotar recursos minerales y energéticos sumamente atractivos.

La posición geoestratégica de las islas Canarias la convierte en un magnífico modelo de análisis de la práctica estatal. La potencial ampliación de la plataforma continental genera solapamientos con Portugal y el Sahara Occidental y ha reactivado dos cuestiones destacadas. Por un lado, la cuestión de las islas Salvajes, que sale de la esfera de la plataforma continental ampliada. Por otro lado, el estatus del Sahara Occidental como territorio no autónomo, que impide la delimitación de los espacios marinos existentes entre este territorio y Canarias.

Es responsabilidad del Estado no perder las oportunidades que le ofrece un tratado como el que codifica de un modo tan exhaustivo el Derecho del mar. Un buen aprovechamiento de las herramientas que la Convención pone a disposición de los Estados ribereños es garantía de poder y acceso a recursos en condiciones legítimas.

Palabras clave: plataforma continental, ampliación, Comisión de Límites, islas Canarias, delimitación marítima, límites, islas Salvajes, Sahara Occidental, Marruecos.

\section{ABSTRACT \\ THE CONTINENTAL SHELF OF THE CANARY ISLANDS: EXTENSION AND RELATED ISSUES}

The United Nations Convention on the Law of the Sea envisages the possibility for coastal States to extend their continental shelf beyond 200 nautical miles. This creates an additional marine space where States can explore and exploit extremely attractive mineral and energy resources.

The geo-strategic position of the Canary Islands provides an excellent example of state practice. The potential extension of the continental shelf leads to overlaps with Portugal and with Western Sahara and has reactivated two outstanding issues. On the one hand, the question of the Savage Islands, which is out of the sphere of the extended continental shelf. On the other hand, the status of the Western Sahara as a non-autonomous territory,

de que el territorio saharaui no forma parte del territorio del Reino de Marruecos, las aguas adyacentes al territorio del Sahara Occidental no están comprendidas en la zona de pesca marroquí, objeto del Acuerdo de pesca, Sentencia de 27 de febrero de 2018, asunto C-266/16, ECLI:EU:C:2018:118. 
which prevents the delimitation of the marine spaces between this territory and the Canary Islands.

It is the State's responsibility not to miss the opportunities offered by a treaty such as this one which exhaustively codifies the law of the sea. A good use of the tools that the Convention makes available to coastal States is a guarantee of power and access to resources under legitimate conditions.

Keywords: continental shelf, extension, Commission on the Limits, Canary Islands, maritime delimitation, boundaries, Savage Islands, Western Sahara, Morocco. 